\title{
Influence of the Particle Size Distribution of Natural Sands in the Accelerated Alkali-Silica Expansion Test (AMBT)
}

\author{
Patricia E. Vila ${ }^{1}$ and María N. Pereyra ${ }^{2}$ \\ ${ }^{1}$ Instituto de Estructuras y Transporte, Facultad de Ingeniería, Universidad de la República, \\ Montevideo, Uruguay, pvila@ fing.edu.uy \\ ${ }^{2}$ Instituto de Estructuras y Transporte, Facultad de Ingeniería, Universidad de la República, \\ Montevideo, Uruguay, mpereyra@fing.edu.uy
}

\begin{abstract}
The accelerated mortar bar test (AMBT) is used to evaluate the potential expansion of the aggregate for the alkali-silica reaction. In this test, the aggregate should meet a certain distribution of particle size. In Uruguay it is usual that for concrete the fine aggregate is constituted by a mixture of sands, one of coarse size and another of fine size. Therefore, coarse sand must be crushed for the test and the fine sand is weighted accumulated in the smallest sieve in which there is enough material according to its particle size distribution. The aim of the work is to evaluate the influence of the particle size distribution of natural coarse sands, without crushing, in the result of the AMBT test. Mortars with different grading composition and single particle size were elaborated, and the differences obtained in the expansion, in the formation of efflorescence on the surface of the bars and in the presence of the reaction gel in the solution where the bars were immersed were analyzed. A greater expansion was observed in the samples with a continuous size distribution, compared with a single particle size. In addition, in the bars elaborated with the largest particle size, a greater amount of gel on its surface and in the solution was observed. The relevance of the work was to improve the reliability of the result in the AMBT test to evaluate the reactivity of the natural coarse sand. Natural sands of siliceous quartzfeldespathic origin were evaluated, without pessimum effect.
\end{abstract}

Keywords: Alkali-Silica Reaction, Accelerated Mortar Bars Test, Natural Sand, Grading Composition.

\section{Introduction}

Concrete is subject to numerous pathological manifestations during its service life. The origin of these pathologies is commonly related to their constituents and their interaction with the environment. The alkali-silica reaction (ASR) is an internal reaction in concrete that occurs between certain components of aggregates considered "reactive" (opal, chalcedony, quartz, tridymite, cristobalite, chert and volcanic glass) and ions form the pore solution of concrete (hydroxyls, alkalis and calcium ions). The reaction products expand in presence of moisture, causing cracking, displacements, structural deformations, pop-outs and reduction in mechanical performances. Service life of structures may be severely affected. In addition, the reaction products can cause leaching stains on concrete surfaces (Nixon and Sims, 2016).

Great efforts have been made to develop test methods to evaluate the aggregate reactivity and the deleterious degree of the reaction. Nowadays, there are several internationally recognized standardized tests, such as the accelerated mortar bar test (ASTM, 2014; IRAM, 1997; ABNT, 2009; AENOR, 2018) the semi-accelerated concrete prism test (IRAM, 2013; Nixon and Sims, 2016) and long-term concrete prism test (with a duration of one year or more) (ASTM, 2015; IRAM, 2013; ABNT, 2009b). The criteria to define the reactivity of the 
aggregate arises from the expansion obtained after the mortar or concrete bars have been submitted in an aggressive environment for a predetermined period of time (Nixon and Sims, 2016; IRAM, 2016; IRAM 2013; ASTM 2018; ABNT, 2009b).

In Uruguay, given the availability of natural sands, the fine fraction of the aggregate in the concrete - portion of an aggregate passing $4.75 \mathrm{~mm}$ sieve and predominantly retained on the $0.15 \mathrm{~mm}$ sieve - usually is obtained by two sands, one identified as "fine sand" and the other as "coarse sand". Coarse sands present large particle size generally the highest proportion in these is retained in the sieves of greater aperture (between $2.36 \mathrm{~mm}$ and $0.30 \mathrm{~mm}$ ). The fine sands usually present particle size between $0.30 \mathrm{~mm}$ and $0.15 \mathrm{~mm}$. Both types of fine aggregates must be mixed to form a suitable particle size distribution to be used in concrete.

The accelerated mortar bar test AMBT test consists in evaluating the variation in length of mortar bars immersed in an aggressive solution of sodium hydroxide at $(80 \pm 5){ }^{\circ} \mathrm{C}$ for a period of 14 to 28 days. This standard procedure indicates that the aggregate under evaluation shall have a specific size distribution. The material must be used in a dry condition, previously washed, with all particle passing through sieve $4.75 \mathrm{~mm}$ and retained at sieve $0.15 \mathrm{~mm}(10 \%$ retained at $2.36 \mathrm{~mm}, 25 \%$ retained at $1.18 \mathrm{~mm}, 0.60 \mathrm{~mm}$ and $0.30 \mathrm{~mm}$ and then $15 \%$ retained at $0.15 \mathrm{~mm})$.

In cases where it is necessary to evaluate the reactivity of a coarse sand-without the presence or with low quantity of the smallest fractions, the standard's procedure indicates that it should be crushed to obtain these fractions. However, the aggregate's textural and microstructural characteristics are altered by the crushing process, affecting its reactivity (Cosentino et al. 2011). In addition, when the process is carried out with a jaw drusher, it is difficult to reach the
necessary quantities for the test in particle size smaller than $0.6 \mathrm{~mm}$.
The aim of the work was to analyses the influence of the particle size distribution in
aggregate in the expansive behavior of the mortar in the AMB T test and to evaluate the anount
of material leached to the $\mathrm{NaCH}$ (sodium hydroxide) solution in which the bars are imnersed. The relevance of the work was to improve the reliability of the result to evaluate the reactivity

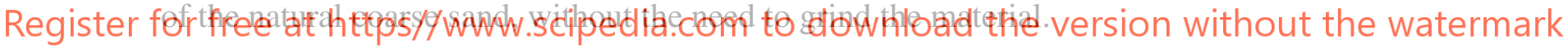

\section{Methodology}

\subsection{Materials}

Two natural sands (identified AGA and AGB) of siliceous quartz-feldespathic origin were taken from the Santa Lucía river. Both sands present potentially reactive component to ASR and after being evaluated in the AMBT test have a higher expansion than the limit of $0.10 \%$ at 14 days of immersion and $0.19 \%$ at 28 days. They do not have a pessimum effect. Table 1 shows the characteristics of the sands used.

Both samples have a Fineness Modulus greater than 2.70 and contain a low quantity of particles smaller than $0.30 \mathrm{~mm}(0.6 \%$ in sample AGA and $1.5 \%$ in sample AGB). At the same time, the AGA sand has only $11.9 \%$ of particles smaller than $0.60 \mathrm{~mm}$. For this reason, they are identified as coarse sand. In Uruguay these sands are used to produce concrete mixture combined with another fine sand. 
Table 1. Characteristics of the sand used for the analysis.

\begin{tabular}{ccc}
\hline Sample Id. & AGA & AGB \\
\hline Origin & Paso Pache, Canelones & Aguas Corrientes, Canelones \\
\hline Summary description & $\begin{array}{c}\text { Natural coarse sand. Quartz- } \\
\text { Feldespathic sand. }\end{array}$ & $\begin{array}{c}\text { Natural coarse sand. Quartz- } \\
\text { Feldespathic sand. }\end{array}$ \\
\hline Potentially reactive component to ASR & $\begin{array}{c}5 \% \text { of quartz microcrystaline } \\
\text { (smaller size than 0.15mm) }\end{array}$ & $\begin{array}{c}\text { 4\% of quartz microcrystaline } \\
\text { (smaller size than 0.15mm) }\end{array}$ \\
\hline Expansion in AMBT test (IRAM 1674) & $0.147 \%(14 \mathrm{~d})-0.236 \%(28 \mathrm{~d})$ & $0.124 \%(14 \mathrm{~d})-0.208 \%(28 \mathrm{~d})$ \\
\hline
\end{tabular}

Sieve distribution

\begin{tabular}{ccc}
\hline Retained at $4.75 \mathrm{~mm} \mathrm{( \% )}$ & 6.0 & 0.2 \\
\hline Retained at $2.36 \mathrm{~mm} \mathrm{( \% )}$ & 15.5 & 2.2 \\
\hline Retained at $1.18 \mathrm{~mm} \mathrm{( \% )}$ & 31.3 & 16.4 \\
\hline Retained at $0.60 \mathrm{~mm} \mathrm{( \% )}$ & 35.2 & 47.7 \\
\hline Retained at $0.30 \mathrm{~mm} \mathrm{( \% )}$ & 11.3 & 31.9 \\
\hline Retained at $0.15 \mathrm{~mm}(\%)$ & 0.4 & 1.4 \\
\hline Plan & 0.2 & 0.1 \\
\hline Fineness Modulus & 3.69 & 2.86 \\
\hline
\end{tabular}

A Normal Portland Cement - identified as CPN by the standard UNIT 20 (UNIT, 2017) was used to produce the mortars. This cement is for general use in concrete and contains only clinker as the main component, without additions. The samples used have an equivalent alkali content $\left(\mathrm{Na}_{2} \mathrm{Oeq}\right.$ ) between $1.16 \%$ to $1.29 \%$, an average autoclave expansion of $0.11 \%$ and a specific surface (Blaine) 2.2 Accelerate Mortar Bars Test (AMBT) The accelerated mortar bars test was performe for the particle size distribution of the aggregate
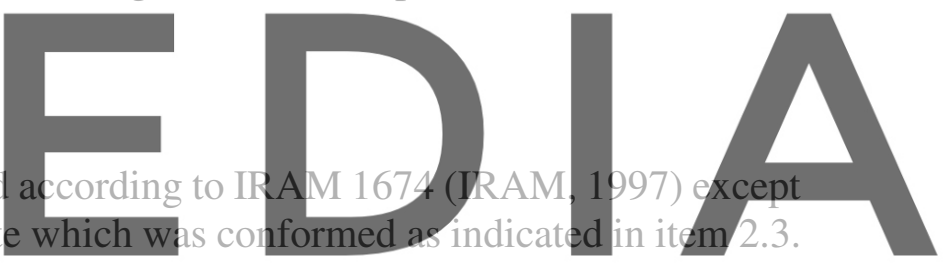

Three bars were casted for each mortar. The bar sizes were in all cases 25x25x285 (mm x mm

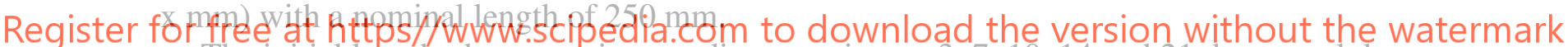
The initial length, the one at intermediate test times - 3, 7, 10, 14 and 21 days - and the one at the end of the immersion period were recorded for each bar during 28 days of immersion in the aggressive solution of $1 \mathrm{~N} \mathrm{NaOH}$ at $(80 \pm 5){ }^{\circ} \mathrm{C}$. The expansion of each bar at a certain immersion age $t i$ was calculated as the difference between the length at the age $t i$ and the initial length at $t 0$. This was referred to the nominal length of the bar $(250 \mathrm{~mm})$ in percentage.

The mortar expansion is calculated as the average expansion of the three bars tested. The coefficient of variation per sample was calculated to verify the accuracy of measurements of the different bars, according to the limits indicated by the ASTM C1260 (ASTM, 2014).

\subsection{Particle Size Distribution in AMBT Test}

Five particle size distribution were analyzed for each sand: four mixtures were fabricated with a single grading size $(2.36 \mathrm{~mm}, 1.18 \mathrm{~mm}, 0.60 \mathrm{~mm}$ or $0.30 \mathrm{~mm})$ and one mixture (identified as reference) was fabricated with different grading size composition according to the particle size distribution and considering the standard procedure but without crushing the sample (Table 2). 
Patricia E. Vila and María N. Pereyra

Table 2. Particle size distribution for mixture in AMBT test.

\begin{tabular}{cccccccccccc}
\hline \multicolumn{1}{c}{ Sieve size } & \multicolumn{1}{c}{ AGA sample } & \multicolumn{1}{c}{ AGB sample } \\
\hline $\begin{array}{c}\text { passing } \\
(\mathrm{mm})\end{array}$ & $\begin{array}{c}\text { retained } \\
(\mathrm{mm})\end{array}$ & $\begin{array}{c}\text { AGA } \\
\text { (reference) }\end{array}$ & $\begin{array}{c}236 \\
\text { AGA }\end{array}$ & $\begin{array}{c}118 \\
\text { AGA }\end{array}$ & $\begin{array}{c}600 \\
\text { AGA }\end{array}$ & $\begin{array}{c}300 \\
\text { AGA }\end{array}$ & $\begin{array}{c}\text { AGB } \\
\text { (reference) }\end{array}$ & $\begin{array}{c}236 \\
\text { AGB }\end{array}$ & $\begin{array}{c}\text { AGB } \\
\text { AG }\end{array}$ & $\begin{array}{c}600 \\
\text { AGB }\end{array}$ & $\begin{array}{c}300 \\
\text { AGB }\end{array}$ \\
\hline 4.75 & 2.36 & 10 & 100 & - & - & - & 10 & 100 & - & - & - \\
\hline 2.36 & 1.18 & 25 & - & 100 & - & - & 25 & - & 100 & - & - \\
\hline 1.18 & 0.60 & 65 & - & - & 100 & - & 25 & - & - & 100 & - \\
\hline 0.60 & 0.30 & - & - & - & - & 100 & 40 & - & - & - & 100 \\
\hline 0.15 & pan & - & - & - & - & - & - & - & - & - & - \\
\hline
\end{tabular}

The AGA sample presented low quantities of particles smaller than $0.6 \mathrm{~mm}$. For this reason, the reference mortar included $10 \%$ retained at $2.36 \mathrm{~mm}, 25 \%$ retained at $1.18 \mathrm{~mm}$ and $65 \%$ retained at $0.60 \mathrm{~mm}$. In the AGB sample the reference mortar included $10 \%$ retained at 2.36 $\mathrm{mm}, 25 \%$ retained at $1.18 \mathrm{~mm}$ and $0.6 \mathrm{~mm}$ and $40 \%$ retained at $0.30 \mathrm{~mm}$.

\subsection{Concentration and Chemical Composition of Leachate in $\mathrm{NaOH}$ Solution.}

The suspended solid content in the $\mathrm{NaOH}$ solution in which the bars were previously immersed during 28 days in AMBT test was determined. This was made by filtering a fraction of the solution on Filter Paper Grade 43 and quantifying the mass of solids retained in dry condition.

The elemental chemical composition (percentage referred to the mass of the suspended solid

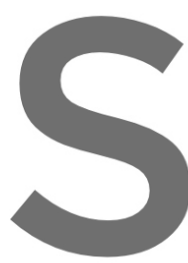
in dry condition) was the interest of this analysis would be indicating th eventually without causi The equipment usec was to detect the presermined using a p
at alkal silica ceaction too
sing expansion.
d was considered adec
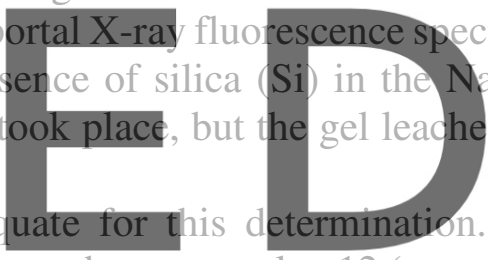

quantifies elements with an atomic number greater than or equal to 12 (among the elements that

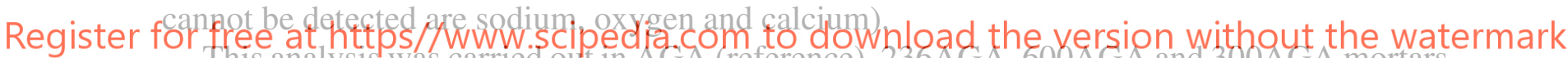
This analysis was carried out in AGA (reference), $236 \mathrm{AG}$, $600 \mathrm{AG}$ A and $300 \mathrm{AGA}$ mortars.

\section{Results}

\subsection{Expansion and Appearance of the Bars in AMBT Test}

Figure 1 shows the expansion evolution for mortar bars fabricated with AGA sand samples and Figure 2 shows the expansion evolution for mortar fabricated with AGB samples.

For AGA (reference) with particle size composition two identical mortars were fabricated (identified as AGA M1 and AGA M2). At 236AGA three identical mortars were fabricated (identified as 236AGA M1, 236AGA M2 and 236AGA M3). For 118AGA one mortar was fabricated (id. as 118AGA M1). For 600AGA two identical mortars were fabricated (id. as 600AGA M1 and 600AGA M2). For 300AGA one mortar was fabricated (id. as 300AGA M1).

For AGB (reference) with particle size composition two identical mortars were fabricated (identified as AGB M1 and AGB M2). For 236AGA three identical mortars were fabricated (identified as 236AGB M1, 236AGB M2 and 236AGB M3). For 118AGB two mortars were fabricated (id. as 118AGB M1 and 118AGB M2). For 600AGA two identical mortars were fabricated (id. as 600AGB M1 and 600AGB M2). For 300AGA two identical mortars were 
fabricated (id. as 300AGB M1 and 300AGB M2).

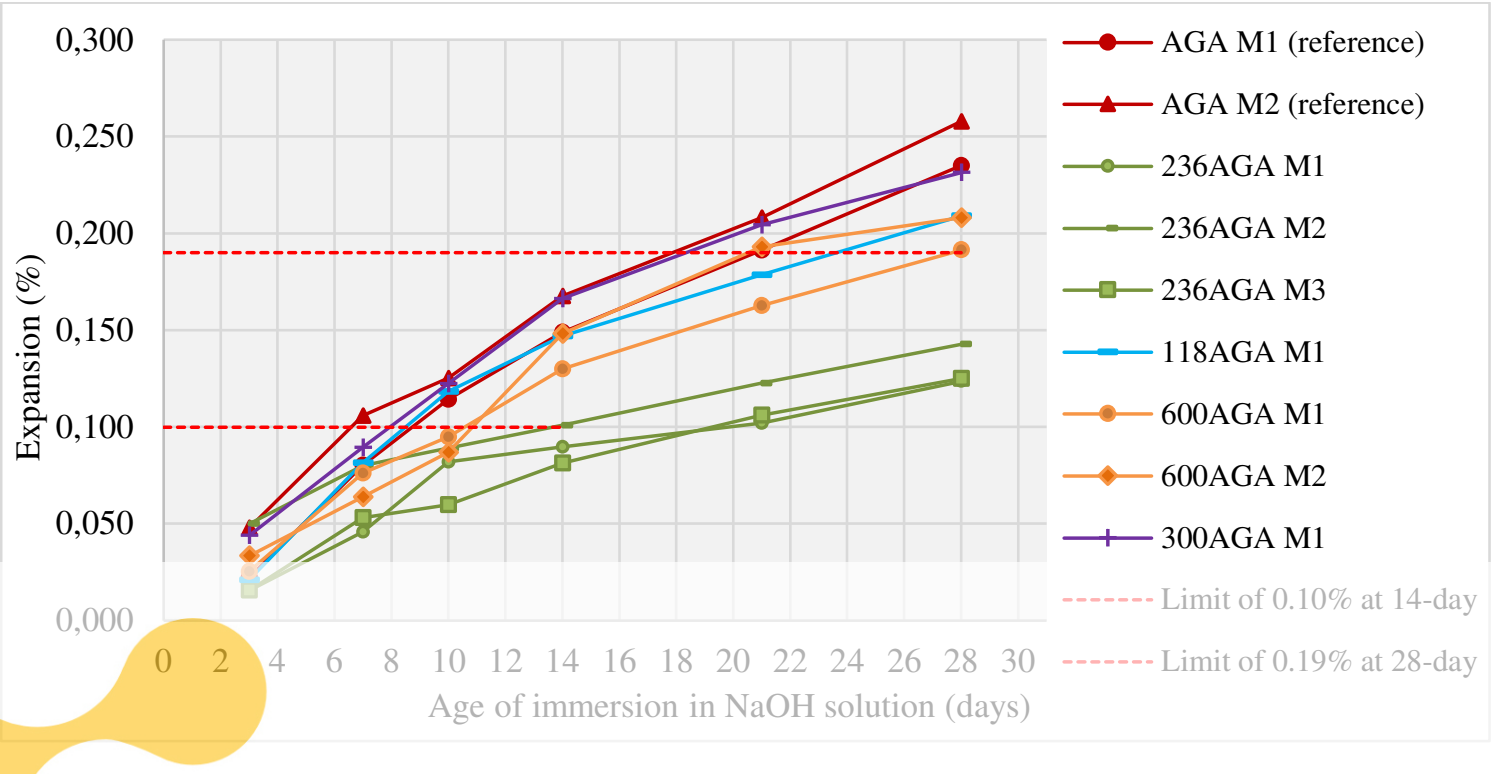

Figure 1. Expansion evolution in AMBT test. AGA sand sample.
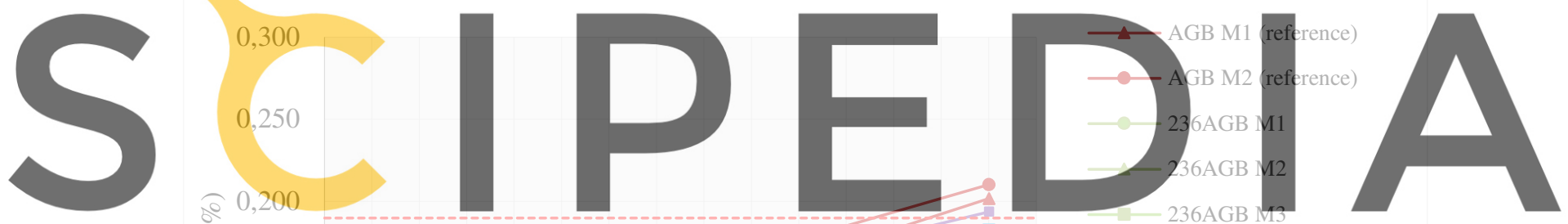

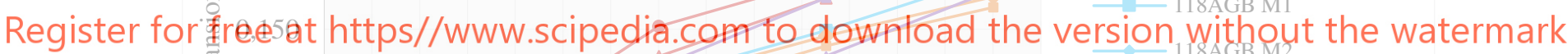
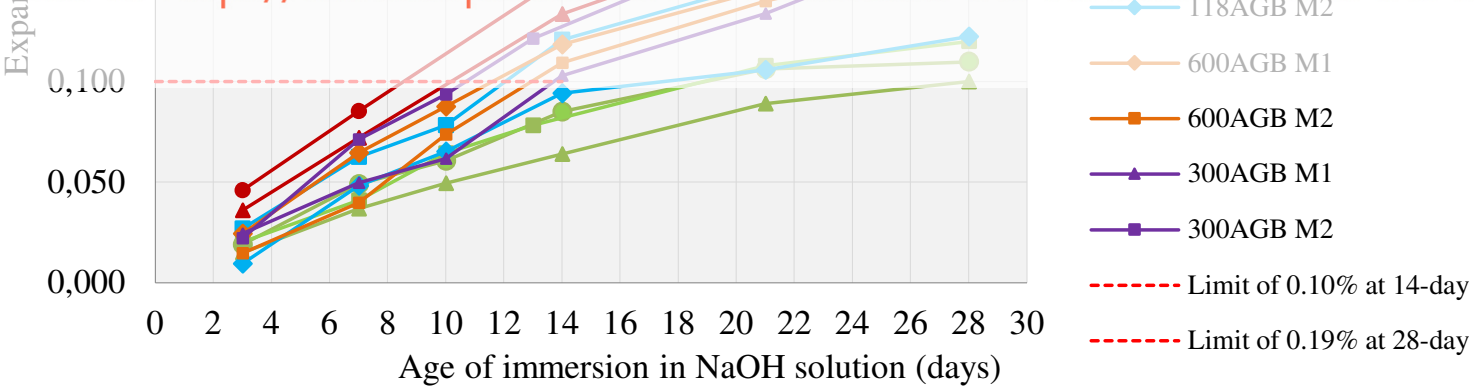

Figure 2. Expansion evolution in AMBT test. AGB sand sample.

Mortar fabricated with grading composition size (reference) according to Table 2 presented the greatest expansion in both AGA and AGB sand. In these cases, the expansion is above standard limits considered in AMBT test $(0.10 \%$ at 14 days and $0.19 \%$ at 28 days).

Mortars fabricated with a single particle size of $2.36 \mathrm{~mm}$ (identification 236AGA and 236AGB) presented the slowest expansion in both sand samples. In both cases, the expansion is below the standard limits. 
Mortar fabricated with a single particle size of $0.60 \mathrm{~mm}$ (600AGA, 600AGB) and $0.30 \mathrm{~mm}$ (300AGA, 300AGB) presented an intermediate expansion. In these cases, all mortars exceeded the expansion limit at 14 days; while at 28 days some samples present an expansion above and others below the limit.

In the case of the 118AGA and 118AGB mortars fabricates with a single particle size of 1.18 $\mathrm{mm}$, two of them presented an intermediate expansion (118AGA M1 and 118AGB M1) and one (118AGB M2) presented a low expansion, similar to 236AGB M1.

During the test and once it was finished, the bars were visually inspected. Cracking on its surface was not observed to the naked eye but different efflorescence degrees, depending on the mortar, were observed (Figure 3). In addition, a leachate to the $\mathrm{NaOH}$ solution was observed in some mortars.

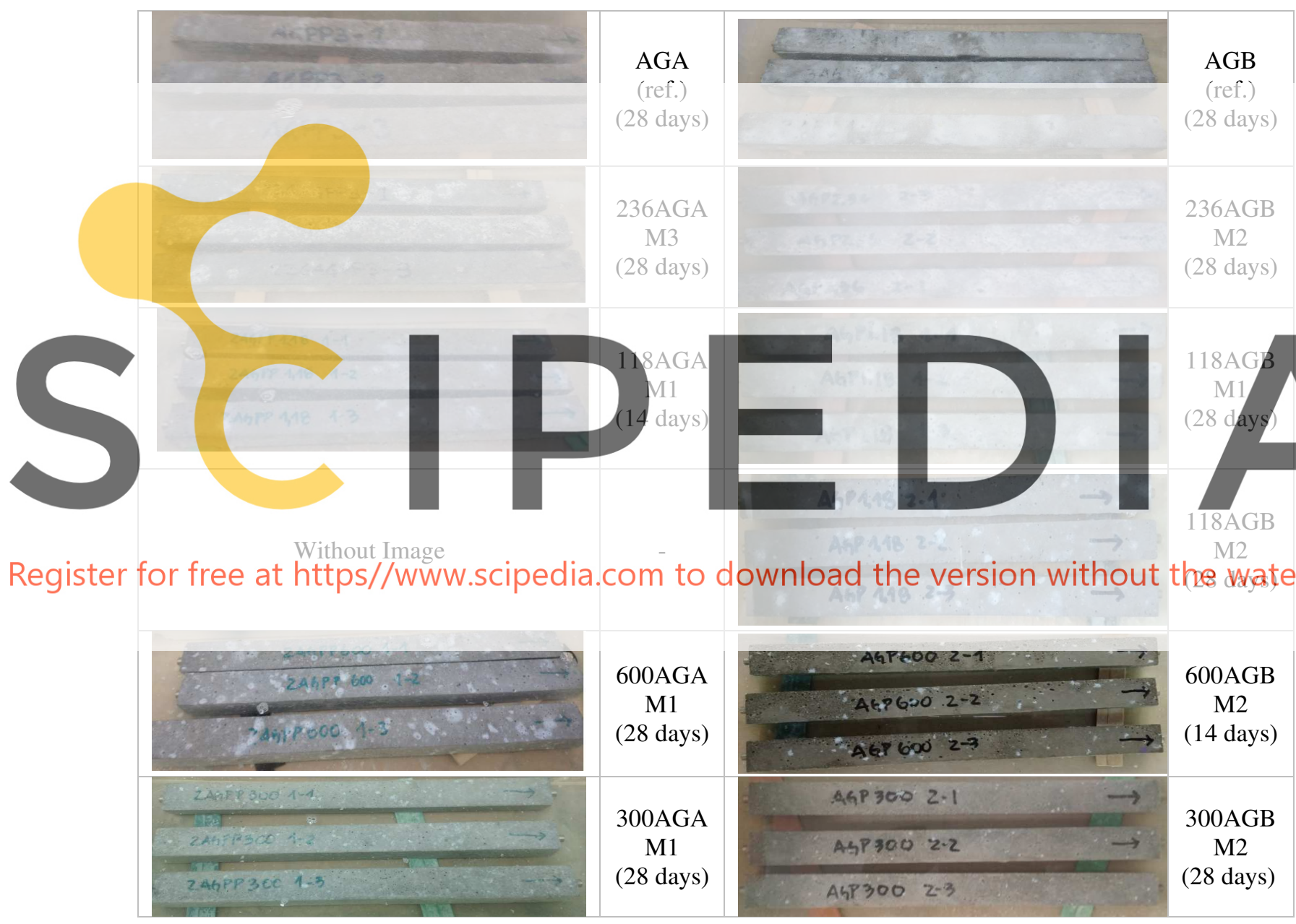

Figure 3. Images of bars fabricated with different particle sizes at the end of the AMBT test.

Bars fabricated with a single particle size of $0.30 \mathrm{~mm}$ (300AGA and 300AGB) had a small amount of tiny efflorescence on their surface.

Bars fabricated with a single size of $0.60 \mathrm{~mm}$ (600AGA, 600AGB) and 1.18mm (118AGA and 118AGB M2) had the highest amount of efflorescence. However, the surface of the 118AGB M1 mortar looked different from the 118AGB M2 mortar but it was similar to mortars 
fabricated with a single particle size of $2.36 \mathrm{~mm}$ (236AGA and 236AGB). In those cases, a discoloration of the surface and leached material in the $\mathrm{NaOH}$ solution were observed.

The bars fabricated with the reference mortar (AGA and AGB) presented a discoloration of the surface, similar to 236AGA and 236AGB.

\subsection{Concentration and Chemical Composition of Leachate in $\mathrm{NaOH}$ Solution}

Concentration and chemical composition of the leachate from the bars to the $\mathrm{NaOH}$ solution were determined. The evaluation was carried out only in mortars fabricated with AGA sand (Table 3).

Table 3. Leachate in the $\mathrm{NaOH}$ solution analyzed.

\begin{tabular}{cccccccc}
\hline Id. sample & Concentration & \multicolumn{5}{c}{$\begin{array}{c}\text { Chemical composition of elements with an atomic } \\
\text { number greater than or equal to 12 (\% referred to the } \\
\text { mass of the suspended solid in dry condition) }\end{array}$} \\
\cline { 2 - 7 } & $\mathrm{g} / 1$ & $\mathrm{Si}$ & $\mathrm{Ca}$ & $\mathrm{K}$ & $\mathrm{S}$ & $\mathrm{Al}$ & $\mathrm{Fe}$ \\
\hline AGA (ref.) M2 & 0.91 & 22.7 & 55.2 & 2.1 & 1.5 & 4.6 & 0.9 \\
\hline 236AGA M3 & 1.34 & 18.8 & 32.9 & 2.0 & 1.3 & 2.1 & 0.5 \\
\hline 600AGA M2 & 0.81 & 8.1 & 14.1 & 1.2 & 2.4 & 0.4 & 0.3 \\
\hline 300AGA M1 & 0.01 & - & - & - & - & - & - \\
\hline
\end{tabular}

The 300AGA M1 bars did not present significant amounts of leached material to the solution

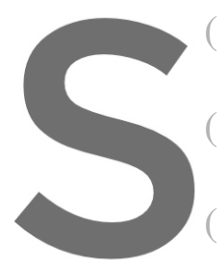
(0.01 g/l).
Bars fabricated with 600AGA M2 presented leached material $(0.81 \mathrm{~g} / \mathrm{l})$ The presence of Si
(silica) was detected in $8.1 \%$ using the X-ray technique.
Bars fabricated with $236 \mathrm{AGA}$ M3 presented leached material $(1.34 \mathrm{~g} / 1)$. The presence of Si
(silica) was detected in $18.8 \%$.
Bars fabricated with AGA (reference) M2 presented leached material $(0.91 \mathrm{~g} / \mathrm{f})$. The

Register for free at https//WwW.scipedia.com to download the version without the watermark

\section{Conclusions}

- The influence of the particle size distribution on the expansion of the mortar in AMBT test was observed. The potential reactivity of the aggregate arises from the expansion parameter. This could lead to erroneous conclusions when evaluating natural sands considering they do not present a continuous particle size distribution. For both sand samples, the greatest expansion was presented in mortars fabricated with different grading size composition (reference) and the lowest expansion was presented in mortars with a single size of $2.36 \mathrm{~mm}$.

- At the same sand sample, different behaviors - discoloration, efflorescence, leached material- were observed to the naked eye according to the particle size composition in both sands included in the analysis. This difference was caused by a change in the mortar microstructure. The greatest surface efflorescence was presented in mortars fabricated with a single particle size of $1.18 \mathrm{~mm}$ and $0.60 \mathrm{~mm}$.

- The evaluation of the leachate concentration and its chemical composition allowed detecting the presence of the silica in the $\mathrm{NaOH}$ solution. Bars fabricated with the smallest size particle of $0.30 \mathrm{~mm}$ exhibited negligible leachate. However, the bars 
fabricated with the largest particle size of $2.36 \mathrm{~mm}$ presented the largest amount of leached material. In this cases silica was detected in the $\mathrm{NaOH}$ solution so the alkali silica reaction took place, but the gel leached into the solution. The evaluation was performed only on a sand sample (id AGA).

\section{Acknowledgements}

Thanks to the Structures and Transport Institute (IET) of the Engineering University (UdelaR) for the equipment and laboratory necessary to carry out the test, as well as the CSIC (Science Investigation Committee - UdelaR) and Concrexur S.A. for the project financing and the private companies that provided the materials for the study.

\section{ORCID}

Patricia Vila: https://orcid.org/0000-0001-8902-5180

María Noel Pereyra: CVuyMPereyra

References

Nixon, P and Sims, I. (2016). RILEM Recommendations for the Prevention of Damage by Alkali-Aggregate Reactions in New Concrete Structures, State-of-the-Art. Report of the RILEM Technical Committee 219-ACS.

ASTM (2014). ASTM C1260: Standard Test Method for Potential Alkali Reactivity of Aggregates (Mortar-Bar Method), ASTM International, West Conshohocken, PA, 2014, www.astm.org.

IRAM (1997). IRAM 1674 Agregados. Determinación de la Reactividad Alcalina Potencial Método Acelerado de la Barra de Mortero (in Spanish), Instituto Argentino de Normalización y Certificación, Argentina.

ABNT (2009). ABNT NBR em barras de argamas Brasil.

AENOR (2018). UNE 1465 álcali-silicato de los áridos. Método acelerado en Normalización y Certificación, España.

IRAM (2013). IRAM 1700. Agregados. Método para la determinación del cambio de largo en prismas de
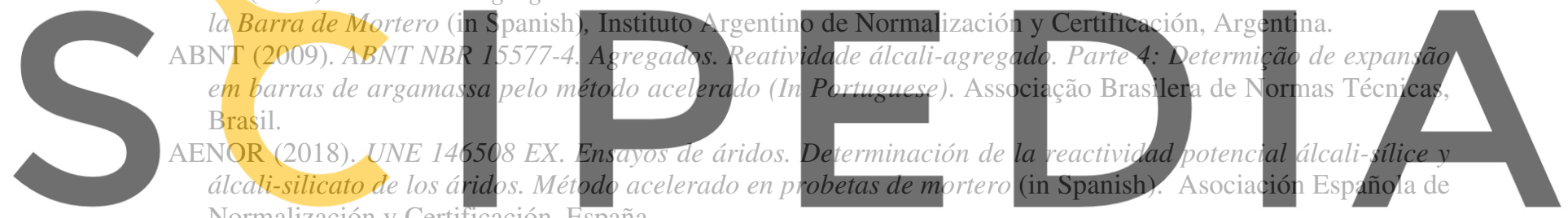

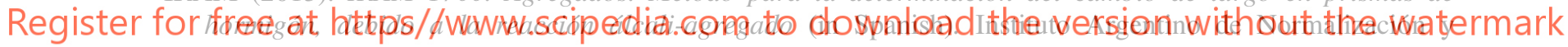
Certificación, Argentina.

ASTM (2015). ASTM C1293-08b: Standard Test Method for Determination of Length Change of Concrete Due to Alkali-Silica Reaction, ASTM International, West Conshohocken, PA, 2015, www.astm.org.

ABNT (2009a). ABNT NBR 15577-6. Agregados-Reatividade álcali-agregado Parte 6: Determinação da expansão em prismas de concreto (In Portuguese). Associação Brasilera de Normas Técnicas, Brasil.

IRAM (2016). IRAM 1531. Agregdo gureso para hormigón de cemento. Requisitos y métodos de ensayo (in Spanish). Instituto Argentino de Normalización y Certificación, Argentina.

IRAM (2013). IRAM 1512. Agregdo fino para hormigón de cemento. Requisitos (in Spanish). Instituto Argentino de Normalización y Certificación, Argentina.

ASTM (2018). ASTM C33 C33M-18, Standard Specification for Concrete Aggregates, ASTM International, West Conshohocken, PA, 2014, www.astm.org.

ABNT (2009b). ABNT NBR 15577-1. Agregados-Reatividade álcali-agregado. Parte 1: Guia para avaliação da reatividade potencial e medidas preventivas para uso de agregados em concreto (In Portuguese). Associação Brasilera de Normas Técnicas, Brasil.

Cosentino, J. Sota, J. and Avid, F. (2011). Forma y tamaño de las partículas y su incidencia en el resultado del método de ensayo ASTM C-1260 (in Spanish). Concreto y Cemento. Investigación y Desarrollo. 2011, 3(1), 14-24. ISSN: 2007-3011. Available in: https://www.redalyc.org/articulo.oa?id=361233549002

UNIT (2017). UNIT 20. Cemento pórtland para uso general. Definiciones y requisitos (in Spanish). Instituto Uruguayo De Normas Técnicas, (Montevideo, Uruguay), p. 13. 